\title{
Rhetoric and Anti-Semitism
}

\author{
Lawrence A. Lengbeyer
}

1.

Charges of anti-Semitism continue to be potent weapons of moral and intellectual critique in our culture. It is good that these have a place in our arsenal-though, of course, it is best when they need not be wielded, when their mere presence deters the activities that would evoke them. On the other hand, they can, like all weapons, be misused, and the mere anticipation of being on the receiving end of such misuse can deter activities that are not in fact anti-Semitic and ought not rightly be deterred. This seems particularly worrying when the activities consist solely of the expression of ideas, placing them in a category that our social and political tradition makes us especially loathe to inhibit. Clearly, then, it is important that we work toward a clear understanding about just what sorts of conduct and circumstances warrant charges of anti-Semitism.

Because so many of the behaviors that might be classified as anti-Semitic consist of or include the verbal expression of ideas, one logical place to turn for assistance is to those who have expertise in the understanding and analysis of rhetoric. We would expect such specialists to be of value both in assessment of particular allegations of anti-Semitism, and in the broader reflections needed for clarifying the lines between anti-Semitism and morally legitimate activity. In questions of bigotry, as elsewhere, words matter; who, then, better to delineate the subtle line between bigoted and unbigoted expression than those whose central disciplinary practice is the sensitive elucidation of discourse, the perceptive explication of utterances and texts?

And who better, in that case, than a prolific scholar who is both the Maxine Elliot Professor in Rhetoric and Comparative Literature at the University of California, Berkeley and the Hannah Arendt Professor of Philosophy at the European Graduate School? The renowned Judith Butler, in a substantial lead essay in the London Review of Books, ${ }^{1}$ takes up the challenge, examining whether charges of anti-Semitism are appropriately lodged against those whose expressive acts target the state of Israel and its policies.

Alas, any expectations of conceptual clarification, or hopes for definitive guidance about how to assess verbal expressions of bigotry, are profoundly,

Lawrence A. Lengbeyer teaches ethics and philosophy in the Department of Leadership, Ethics, \& Law at the United States Naval Academy, Annapolis, MD 21402. 
even rudely, disappointed. Instead of a felicitous encounter between subjectmatter and subject-matter expert, Butler's article displays a celebrated rhetorician's inability to extract the most obvious, accessible meaning from a not terribly sophisticated text, as well as a supposed philosopher's inability to avoid basic missteps of logic. Butler can certainly be credited with writing a provocative article. Unfortunately, what it provokes is consternation at the missed opportunity for enlightenment, concern that it could promote the degeneration of political discussion, doubt about the intellectual standards of her discipline, and apprehension lest the norms of philosophical practice in Europe gain wider acceptance in the Anglo-Aussie-American world.

\section{2.}

The occasion of Butler's expedition into the territory of anti-Semitism is a recent brief address on the subject by Harvard president Lawrence Summers. ${ }^{2}$ Summers cites "disturbing evidence of an upturn in anti-Semitism globally" that is directed not only at Jews themselves, but also at the physical sites and historical narratives with which Jews are associated (and by which Jewish identity and community are, in part, maintained), as well as at Israel, the nationstate that was founded for the sake of Jewish safety and flourishing. His more specific concern, though, is with corresponding developments within the academy. In his view, whereas

anti-Semitism and views that are profoundly anti-Israeli have traditionally been the primary preserve of poorly educated right-wing populists, profoundly antiIsrael views are increasingly finding support in progressive intellectual communities. Serious and thoughtful people are advocating and taking actions that are anti-Semitic in their effect if not their intent.

Summers then supports and specifies his claim by presenting examples from the academic world, all of which can be construed as attempts to isolate, delegitimize, or otherwise weaken Israel, its institutions, and its (Jewish) citizens. At the same time, he both precedes and follows his listing with clear endorsements of freedom of expression. He affirms that "[o]f course academic communities should . . . allow any viewpoint to be expressed," that "[w]e should always respect the academic freedom of everyone to take any position," and, moreover, that "certainly there is . . much in Israel's foreign and defense policy that can be and should be vigorously challenged."

How does Summers reconcile these two positions? Quite easily: "academic freedom does not include freedom from criticism. The only antidote to dangerous ideas is strong alternatives vigorously advocated." In other words, people ought to be permitted freedom of thought and expression-to adopt and articulate any views whatsoever. But when these views, or the attitudes they support and the behaviors they encourage, are reprehensible (e.g., anti-Semitic), they ought to be countered forcefully, so as to reveal their baseness and under- 
mine the support for them. Ideas do make a difference. They change minds, actions, and, thereby, the world. While we may be obligated, in certain roles (and barring certain special kinds of circumstances), not to squelch their expression, there are times when a moral responsibility is thrust upon us to take up our own pens or voices against them and against their proponents.

Is this one of those times, and are the kinds of activities that Summers listsnamely, calls for university divestment from Israel, and for cutting institutional ties with Israeli researchers (some of whom have indeed been evicted from editorial positions at an international journal); trumpetings of anti-Israel invective at student-fueled anti-globalization demonstrations; campus fundraising for dubious organizations that might have links to anti-Israel terrorism-are such activities deserving of forceful public criticism? We sorely need a careful dissection of the modes of anti-Israel expression, in order to discern the line where, if anywhere, it crosses over into anti-Semitism, as well as guidance in the proper counter-rhetoric to be employed against anti-Semitism. This ought to be fertile ground for an eminent rhetorician-philosopher-especially one, like Butler, with a longstanding research interest in the subordination of societal subgroups and the discourses that aim to effect this.

Unfortunately, Butler misses the central issue that Summers raises, and mangles some of the matters to which she attends. Worse, as we shall see, her intervention is, if anything, likely to increase anti-Semitic behavior, rather than reduce or control it.

3.

Butler does have a useful point to make about the basic distinction between criticism of Israel and criticism, or hatred, of Jews. There are, unfortunately, a good number of people, most of them Jews, who need reminding of this difference. Indeed, we ought to press the point further than Butler, and insist that not only Israel, but all Jewish communities and (sub) cultures, can benefit from constructive critique, and that such critique need not amount to antiSemitism, either. By the same token, of course, the (sub)cultures and organizations of blacks, women, and gays ought to be fair game for probing critique from without and from within, without inevitably raising knee-jerk indignant cries of racism, misogyny, gay-bashing, or self-loathing.

Beyond this elementary proposition, however, and a survey of disparate positions that might be adopted toward the state of Israel's political constitution and policies, Butler's piece has little to offer. Most crucial, she replaces Summers's own expressed views with exaggerated (and less interesting) caricatures, making little effort to engage with the challenging and important question that his address raises, which we can generalize as follows: Can criticism of a state (such as Israel), or other social or political institution or organization (such as the NAACP), ever amount to anti-Semitism, racism, or other 
bigotry against the people represented by or associated with it, even if no explicit denigration of them occurs? ${ }^{3}$ Instead, Butler addresses a trivialized versionwhether such criticism must, invariably, amount to bigotry against those associated with it-and unfairly attributes an affirmative answer on this to Summers.

Granted, Summers does not deliver his question fully formed on a silver platter; but neither does it take sophisticated hermeneutic expertise to extract it from his remarks. He points toward it, and toward an answer to itnotwithstanding Butler's complaint that "if he thinks it possible to voice disapproval [of Israeli policy], he hasn't shown us how to do it in such a way as to avert the allegation of anti-semitism"-by citing specific features of the opposition to Israel that he finds objectionable while also maintaining that he does not condemn the "vigorous challeng[ing]" of Israeli policy as such. Nowhere, contrary to Butler's repeated statements and insinuations, does Summers maintain that all criticism of Israel amounts to anti-Semitism; nor does he "conflate Jews with Israel” or "equat[e] Zionism with Jewishness," nor does his "logic suggest that certain actions of the Israeli state [such as particular military operations in the West Bank] must be allowed to go on unimpeded by public protest." Rather, he offers lists of particular actions that suggest that he thinks-reasonably enough - that the following sorts of discourse and discourse-related behavior might, individually or in certain combinations, amount to anti-Semitism:

(1) singling out Israel for denunciation (and maybe also investment boycotting, questioning of its historical legitimacy, and even denial of its right to continued existence), while overlooking or downplaying other states' comparable, or more dubious, origins and conduct, including where these defects are more blatant and better documented than those of Israel;

(2) purveying or passing on anti-Israel ideas that are deceptive by virtue of being false, one-sided, otherwise misleading, or emotionally manipulative (and that are, or ought to be, known or suspected to be such)-including, for instance, comparing, as equivalent or nearly so, the activities, beliefs, or personalities of Israelis with others that are grossly more corrupt, evil, or otherwise despicable, such as equating Ariel Sharon with Adolf Hitler, Israel with Nazi Germany, and Israeli policies in the West Bank and Gaza with crimes against humanity and ethnic cleansing à la the Rwandan Hutus' genocidal rampage or the Bosnian Serbs' campaign of massacre, rape, and village-burning;

(Butler may be guilty of this practice herself: in her second paragraph, she effaces the crucial moral disparity between the inadvertent Israeli killing of an innocent Palestinian and the intentional killing by Palestinians of an innocent Israeli Jew, on the grounds that both produce equally dead victims. She even slants the comparison by portraying only the generic Palestinian victim as a child, as though Israeli children do not also continue to die. But even this rhetorical ploy cannot eliminate the vital, and widely recognized, difference in blameworthiness between intentional and unintentional killings.) 
(3) calling for Israeli scholars, merely for their being Israeli, to be punished for the country's actions by being cut off from research support and evicted from scholarly enterprises, again where such a tactic is not similarly extended to the scholars of other nations; and

(4) taking Israel (and perhaps also its supporters) to task while failing to get comparably exercised about (student-led) fundraising for organizations that are found to be supporting anti-Israel terrorism.

The non-autobiographical portion of Summers's address largely comprises a listing of items in these categories-though one would gain no idea of this from reading Butler's hatchet job on the Harvard president. The address makes clear that Summers is not saying, "Don't criticize Israel"; he is saying, "Don't take your criticism past this (not yet well-marked) line where it turns improper." His problem is not with criticism of Israel as such, but with selective and slanted criticism, with criticism that misleads, deceives, or unjustifiably inflames because it fails to supply a reasonably informative context-whereupon it fails to assist the audience in understanding the charges fairly and fails to counteract the cognitive limitations that incline them to do otherwise. It applies an unwarranted double standard, and also, as any effective double-dealing must, hides this fact about itself.

Butler, one would think, given her domain of expertise, would be particularly perceptive regarding this important distinction. Yet, incredibly enough, she misses these important issues entirely, and instead flails away at a simplistic false image of Summers's position. She does briefly note in her opening paragraph that Summers expresses disquiet about the singling out of Israel as a target of political agitation-yet she moves on without ever giving this, the very core of his concern, so much as a backward glance. Moreover, she reads Summers as suggesting that singling out Israel for opposition might constitute "evidence of anti-Semitic intentions." But the interesting question is not whether singling out signals the presence of anti-Semitism, but whether it is ever itself wholly or partly constitutive of (intentional, or perhaps unintentional) antiSemitism. Surprisingly, then, it is the economist Summers who proves to be sensitive to the subtle factors that affect how discourse is received, and therefore how it ought to be morally evaluated, while it is the reputed expert in rhetoric and communication Butler who renders the simplistic readings and has the tin ear.

4.

Butler might well not intend for any of her readers to condemn or dislike Summers, or to take actions aimed at harassing, demonizing, or weakening him. Yet these are foreseeable consequences of her tendentiously selective caricature of his address. We might therefore say that her piece is "anti-Summers" in effect, if not in intent.

This is, is it not, a familiar, straightforward understanding of the phrase 
"actions that are $\mathrm{X}$ in their effect if not their intent"? Yet Butler is greatly vexed by Summers's use of such a concept in his above-quoted statement that "Serious and thoughtful people are advocating and taking actions that are anti-Semitic in their effect if not their intent," and she directs her analytical weaponry toward subverting the effect-intent distinction.

The result is embarrassing, rather than illuminating. Butler makes needless heavy weather of the distinction in question, producing only a contrived, awkward, and unconvincing interpretation of what Summers means by it and stumbling into numerous elementary logical fallacies. The source of this misguided effort is apparently her determination to employ, and display, the (formerly trendy, but now perhaps thoroughly entrenched) method of deconstruction. Her sophomoric exercise, which begets only confusion and incoherence, should arouse the concern, if not alarm, of anyone who has a stake in the practices and standards of her discipline(s).

First of all, notice that Butler herself, notwithstanding her objective of obliterating the "in effect X" notion, calls elsewhere in her piece upon the very same ordinary understanding of it that I have just described. She suggests that, if Summers's words have "a chilling effect on political discourse"-which has already happened, she claims, though without offering supporting evidence-then he "has struck a blow against academic freedom, in effect, if not in intent." Clearly, the conceptual distinction between intentional X-ness and effective X-ness is not an arcane one. We quite commonly talk of behaviors or choices that bring about certain consequences, though unintentionally-and we use "in effect" terminology to do so.

Even more egregious, Butler's reasoning betrays several of the basic logical fallacies that she surely instructs her own students to avoid (or so we must hope). Consider this summary of her argument:

(1) Summers holds that any and all criticism of Israel constitutes at least effective anti-Semitism.

(2) "Effective anti-Semitism" must refer to either (i) expressive acts that "can only be interpreted as showing ... [that] the speaker ... hates Jews or is willing to fuel those who do," or (ii) expressive acts that "will be exploited by those who want to see not only the destruction of Israel but the degradation or devaluation of Jewish people in general."

(3) If the former, "the effective anti-semitism of any criticism turns out to reside in the intention of the speaker as retrospectively attributed by the listener." ("But," she later worries, "what if those others are wrong? If we take one form of antisemitism to be defined retroactively, what is left of the possibility of legitimate protest against a state. ... ?")

(4) If the latter, the expressive act supposedly "gives fodder to those with anti-semitic intentions, who will successfully co-opt the criticism. Here again, a statement can become effectively anti-semitic only if there is, somewhere, an intention to use it for anti-semitic purposes."

(5) Thus (the triumphantly delivered coup de grace), "Summers's distinction between effective and intentional anti-semitism . . . collapses." Whichever of the 
two ways we understand the former notion, it reduces to the latter; the conceptual opposition between them is illusory. "Effective anti-Semitism" is ultimately a pointless, redundant concept, having no value for moral appraisal.

By following a recipe from the post-structuralist cookbook, Butler has, she thinks, delivered an impressive dichotomy deconstruction. ${ }^{4}$ Not so fast, however. By my count, Butler in this sequence of claims commits at least four elementary fallacies: Straw Man, Slippery Slope, Equivocation, and False Dilemma. First, Straw Man: Butler attacks a representation of Summers that is not true to the facts of his Harvard address, repeatedly mischaracterizing his position. For one thing, though she initially restrains herself from reading him as intending to chill political discourse, she quickly shifts (again without evidence) to ascribing such a purpose, stating that he "uses the 'anti-semitic' charge to quell public criticism of Israel." More important, Butler cannot restrain herself from unfairly projecting upon Summers a view that he has expressly disavowed, the view that any and every criticism of Israel amounts to anti-Semitism, that "every time the word 'Israel' is spoken, the speaker really means 'Jews." Butler thus portrays Summers in a false light, whether out of malice, a reckless impulse to tell her audience what it wants to hear, or simple carelessness.

Next, Slippery Slope: In (3) above, Butler urges us to be troubled by the after-the-fact nature of the attribution of effective anti-Semitism. But this issue is plainly irrelevant. It is simply truistic that anti-Semitic behavior is characterized retrospectively-what alternative is there? (Retroactivity might thus be a Red Herring-still another logical flaw.) What seems really to concern Butler here is not the fact of retrospective attribution, but the prospect of false, or overbroad, charges of anti-Semitism. Fair enough; this is a real, ever-present concern. But does it follow, as she implies, that defining one category of antiSemitism by audience reaction must tarnish, and delegitimize, all anti-Israel activity? That each of us who issues criticisms of Israel is at the mercy of our audience, on Summers's account, and liable to end up guilty of anti-Semitism?

Actually, the slide down that slope is not at all inevitable. We all possess powerful rhetorical means for guiding and constraining the reasonable construals placed upon our utterances and acts. By utilizing these carefully and conscientiously in order to inhibit the anti-Jewish consequences of our criticisms of Israel (or of Jews), we fulfill our moral responsibilities and avoid or rebut charges of effective anti-Semitism. Knowing, moreover, that we can do this, we see that we need not silence ourselves. Indeed, Butler herself takes painstaking (and successful) precautions to show any reasonable reader that she has no animus against Jews and desires that they not be unjustly victimized-which demonstrates that we do have substantial control over how our acts are received, and that our ethical norms dictate that we exercise this control.

As for Equivocation: In her haste to deny the effect-intent distinction, But- 
ler misleadingly shifts, not once but twice, between two distinct meanings of the word "intention," erasing vital moral differentiations as she goes. First, in (3) she ignores the distinction between someone's actual intent, and the intent ascribed to him by an audience-as if these do not often diverge, with important implications for moral assessment. Second, in (4) she ignores the distinction between the intentions of the utterer/actor, and those of his audience — as if being effectively anti-Semitic is as blameworthy as being intentionally anti-Semitic, even if the only actual anti-Semitic intent involved in the former is that of the audience.

More than that, Butler is wrong to think that effective anti-Semitism presupposes the involvement of anyone with anti-Semitic intentions-which brings us to the False Dilemma upon which her argument rests. Butler writes (see (2)) as if there are only two possible interpretations for the notion of effective antiSemitism-where observers ascribe anti-Semitic intent to the utterer/actor, or where observers exploit the utterance/act for their own preexisting antiSemitic purposes. But this is false: other possibilities certainly exist, and Butler simply, perhaps conveniently, overlooks them. For instance, suppose that an audience encounters utterances that are in fact false or slanted (due to ignorance or carelessness), but takes them to be simple statements of true fact by someone who is not anti-Semitic, has no anti-Semitic agenda, and has said nothing anti-Semitic. Their acceptance of these "truths" then leads them to adopt anti-Semitic attitudes or undertake anti-Semitic activities themselves. These people may or may not see their own attitudes or activities as anti-Semitic, and feel animus toward Jews; but they still may have been spurred by the utterances (perhaps without realizing it) to take unwarrantedly anti-Jewish stances or actions. Indeed, they might even be motivated by altruistic impulses toward Jews, and the original utterances could still deserve to be deemed effectively (though not intentionally) anti-Semitic. ${ }^{5}$

Butler's impoverished analysis leaves us unequipped to deal with the crucial practical and moral issues raised by what in fact is a complex constellation of real-world variables:

- When X says or does V, does he intend and want it to spread anti-Semitic animus or inspire anti-Semitic action, or is he innocent of any such aims?

- Does he expect it to be perceived as such by his audience? Should he? Does he foresee that it might be perceived as such by his audience? Should he? And is it so perceived?

- Does $\mathrm{X}$ expect $\mathrm{V}$ to have these anti-Jewish consequences? Is his expectation reasonable? Does X foresee that V might have these anti-Jewish consequences? Should he? What is the relative proportionality of these expected or foreseen consequences to the expected or foreseen benefits of V? Does $\mathrm{V}$ end up in fact having anti-Jewish consequences? Of what kinds? What magnitudes? Are the consequences brought about intentionally, or inadvertently, and if the latter, are reasonable steps taken to avoid or reduce them? Is the anti-Jewishness of the consequences intended, or inadvertent, and if the latter, are reasonable steps 
taken to avoid or reduce it? What alternative courses might $\mathrm{X}$ have taken in order to achieve the purposes of $\mathrm{V}$ ?

- Is the audience already anti-Semitic when it encounters V? Some part of the audience? Is X aware of these facts when he says or does V? Should he be?

o Does $\mathrm{X}$ intend for audience members not already anti-Semitic to become anti-Semitic as a result of encountering V? Does he expect this? Foresee it? Are his expectation and foresight reasonable? And does V actually have this effect?

o Does $\mathrm{X}$ intend for audience members who are already anti-Semitic to become more anti-Semitic, or more securely or more overtly or more actively anti-Semitic, as a result of encountering V? Does he expect this? Foresee it? Are his expectation and foresight reasonable? And does $\mathrm{V}$ actually have this effect?

- Does X intend for V to be encountered only by those who do so directly? Also by those who learn about V second- or third-hand? Also by "eavesdroppers"? Also by those who observe V re-enacted by others? Does X take any steps to expand, or restrict, the dissemination of information about V? If so, of what kinds, and aimed at what audiences? Who does $\mathrm{X}$ expect to encounter V? Who does he foresee might encounter it? Who should he reasonably expect or foresee might encounter it?

One would think that these are the kinds of factors that a rhetorical-philosophical analysis would eagerly and rigorously examine.

5.

Yet Butler evades the difficult issues toward which these multiple rhetorical, mental, and practical parameters point. She is content to confront a simpleminded opponent, many of her readers no doubt admiring her pose of courage in the face of cultural intimidation, of speaking "truth" to the "power" of a Harvard president and his allies who "defend Israel at all costs." But her analysis, with its interspersed pot shots at specific Israeli actions and policies, simply preaches to the choir, forgoing the opportunity to compel their engagement with the moral complexities. Worse, its confusions and stumblings leave behind a murk clouding the waters for those who wade in afterward.

Nor is this the worst that can be said about Butler's piece. More than unenlightening, it is irresponsible. By not acknowledging its pervasive simplifications, it gives her wide readership the impression that the moral complexities do not exist, and that all complaints about anti-Israel agitation being anti-Semitic are baseless-products of confusion or defensiveness, misguided whinings that ought to be ignored. The result will be less heed of even wellfounded concerns, and thereby a decrease in the rationality and justness of public discussion about the Middle East.

Butler's overriding motive, to avert the compromising of academic freedom or chilling of public discourse, is not an unworthy one. But her anxiety is undiscriminating. Shouldn't we want the discouragement and self-censoring of certain kinds of discourse? Isn't there discourse that, in its irrationality and 
aesthetic vacuousness, serves no useful purpose for anyone but the utterers themselves - that has no compensating societal value, not even novelty? The welfare of humankind is unlikely to be enhanced by eliminating the inhibitions that restrain us from publicly expressing every one of our ideas, no matter how incoherent, confused, deceptive, pointless, ill-tempered, uncivil, or malicious. More is not always better.

And who is best positioned to articulate the norms that keep discourse within constructive bounds? Ought not intellectual leaders, like the Harvard president, verbally combat public discourse that is potentially damaging to individuals, to a polity, or to a cultural tradition? If a prominent jurist, well-esteemed author, popular talk-show host, or movie star should begin issuing outrageous and unfounded white supremacist propagandizing, shouldn't other influential persons seek to controvert the claims and shame those who accept and spread them-or ought they muzzle themselves, lest they risk "setting limits on the speakable"? This is not official, governmental censorship-merely damnations and exhortations by individuals, like Summers, whose prior conduct shows that they deserve to be taken seriously. Butler need not apologize for attempting a critique of Summers, nor I for criticizing her-nor Summers for going after those he targeted.

Ultimately, Butler has no cause for complaint with Summers. She enjoins us all to "challenge anti-semitism vigorously wherever it occurs," in "all [its] forms," and Summers offers reason to think that there is a new strain that demands our vigilance. She even advocates the "freezing"-not merely chilling-of some anti-Semitic discourse within academia:

[I]t is important to distinguish between anti-semitic speech which, say, produces a hostile and threatening environment for Jewish students—racist speech which any university administrator would be obliged to oppose and regulate-and speech which makes a student uncomfortable because it opposes a particular state or set of state policies that he or she may defend.

But what is it that Summers is concerned with, if not speech that seems likely to lead-independently of the utterers' intentions, perhaps-to hostility and to menacing, or unjustly discriminatory, behavior toward Jews? Nowhere does he even hint that his objection to anti-Israel activities is that they uncomfortably challenge the worldviews of Israel sympathizers. It ought to be evidentto an expert in rhetoric, at least-that his concerns are that these activities may wrongly inflame anti-Jewish animosities, and that they may be unfair. Criticism of Israel and anti-Semitism "do, disturbingly, work together" at times, as Butler herself grants, though merely in passing. Would that she had seen fit to turn her expertise toward investigating just what sorts of anti-Israeli rhetoric and conduct might well create "a hostile and threatening [or unjustly discriminatory] environment" for Jews generally, and what, short of skittish avoidance of the whole topic, might be done about that. 
Instead, Butler seeks to discredit an attempt to raise this important and fairly pressing question about where to locate the line between bigotry and legitimate critique. She ducks the harder issue completely, distorting Summers's address to manufacture a pretext for taking on a much easier target-as if, were she challenged to articulate a law of sexual assault to handle the subtle swerves and blurry signals of contemporary sexual encounters, she would instead lambaste the dim-witted, retrograde types who dismiss all rape complaints by saying that the women asked for it. Yes, such people still exist, but they are yesterday's problem. Today, there are more difficult and nuanced issues that need illumination, and it is our most highly trained and highly touted minds who ought to be leading the way.

\section{Notes}

1. Judith Butler, "No, it's not anti-semitic," London Review of Books 25, 21 August 2003.<http:/ /www.lrb.co.uk/v25/n16/butl02_.html> (19 August 2003).

2. Lawrence H. Summers, "Address at morning prayers" (Memorial Church, Cambridge, MA, 17 September 2002). <http://president.harvard.edu/speeches/2002/morning prayers.html> (19 August 2003).

3. The interesting follow-up questions, of course, are (i) whether direct criticism of a group's culture or collective membership can ever amount to bigotry even in the absence of explicit denigration; (ii) the same question, but with respect to a single group member who might be taken to represent the group as a whole; and (iii) the same question, but with respect to a now-past (perhaps long past) incarnation of the group or its culture (as in Christian passion plays, or similar cinematic representations, that unfavorably depict the Jews during the time of Jesus).

4. A helpfully clear, detailed, and balanced description of the deconstructive method can be found in Jack Balkin's "Deconstruction's Legal Career" < http:/ / www.yale.edu/lawweb/ jbalkin/articles/deccar1.htm> (16 February 2004).

5. This possible scenario also seemingly refutes another attempt by Butler to box Summers into one of two positions: her claim that his concept of effective anti-Semitism postulates expressive acts that either "will be taken by others as anti-semitic, or received within a given context as anti-semitic." The utterances in the scenario given are neither "taken by others as anti-semitic," nor so "received." 
Copyright of Academic Questions is the property of Transaction Publishers and its content may not be copied or emailed to multiple sites or posted to a listserv without the copyright holder's express written permission. However, users may print, download, or email articles for individual use. 